\title{
Associando Índice de Incesto e de Paternidade para discriminação de agressão sexual entre indivíduos aparentados
}

\author{
Associating the Incest and Paternity Index to discriminate sexual \\ aggression among close blood relatives
}

\author{
Eduardo L. Rodrigues'; Rodrigo G. Garrido ${ }^{2 ; 3}$; Rosângela M. Carvalho²; \\ Cíntia V.F. Santos ${ }^{1}$; Carlos A. Santos ${ }^{1}$
}

\begin{abstract}
Rodrigues EL; Garrido RG; Carvalho RM; Santos CVF; Santos CA. Associando Índice de Incesto e de Paternidade para discriminação de agressão sexual entreindivíduos aparentados. Saúde, Ética \& Justiça. 2013;18(2):00-00.

RESUMO: A violência sexual no Brasil, além de um crime hediondo, é uma questão de saúde pública. Entre as crianças, parentes destacam-se como agressores. Quando um crime de natureza sexual resulta em gravidez, o exame de paternidade consiste no meio de prova mais fidedigno. Este exame consiste em verificar o compartilhamento de alelos entre o pretenso filho e o suposto pai, de modo a atribuir termos probabilísticos à transmissão dos alelos por parte do suspeito em relação a um homem qualquer na população, não relacionado, o que se denomina índice de paternidade. Porém, em casos cujo suposto pai possui vínculo biológico com a vítima, devem-se considerar alguns parâmetros matemáticos de modo a evitar a superestimativa dos valores atribuídos aos índices de paternidade. Torna-se preciso distinguir Alelos Idênticos por Descendência daqueles Idênticos por Estado. A partir de análise comparativa de 3 casos incestuosos foram efetuados cálculos de Índice de Paternidade da maneira usual, considerando o suspeito como não relacionado à vítima e considerando o suspeito como relacionado à vítima, atribuindo a este cálculo a denominação Índice de Incesto. O Índice de Paternidade Combinado foi superior ao Índice Combinado de Incesto em até $10^{3}$ vezes, mostrando que as análises usuais podem superestimar os resultados nos exames de vínculo genético. Assim, propõe-se o uso desta metodologia matemática nos cenários incestuosos a fim de evitar a emissão de laudos equivocados ou estatisticamente sobrevalorizados.
\end{abstract}

PALAVRAS-CHAVE: Violência Sexual; Paternidade; Incesto.

\footnotetext{
${ }^{1}$ Analista, Centro de Análise e Tipagem de Genomas

${ }^{2}$ Perito Criminal, Instituto de Pesquisa e Perícias em Genética Forense/DGPTC/PCERJ

3 Professor do Mestrado em Desenvolvimento Local - UNISUAM

Endereço para correspondência: Eduardo Leal Rodrigues. Rua Leandro Dupré, 967, Vila Clementino, São Paulo-SP CEP: 04025-014. e-mail: rodrigues.dna@gmail.com.br
} 


\section{INTRODUÇÃO}

C om as alterações promovidas pela lei $\mathrm{n}^{\mathrm{o}}$ 12.015 de $2009^{1}$, no art. 213 do Código Penal $^{(1)}$, trocando a palavra "mulher" por "alguém", excluiu-se a especificidade de gênero do sujeito passivo do crime de estupro. Além disso, ocorreu a inclusão de elementos que caracterizavam o tipo penal de atentado violento ao pudor e que, agora, passam a ampliar a redação do crime de estupro ${ }^{2}$. Entretanto, a despeito da nova redação, o exame de corpo de delito continua sendo o principal meio de prova, permitindo tipificar o crime, comprovando lesões, e até identificar suspeitos por meio de análise genética de materiais biológicos coletados, p.ex., no corpo ou em vestes da vítima ${ }^{3}$.

Além disso, a violência sexual no Brasil, além de um crime hediondo, pode ser considerada um problema de saúde pública4. Segundo o Fórum Brasileiro de Segurança Pública ${ }^{5}$, o índice de estupros aumentou $18 \%$ entre 2011 e 2012, alcançando 26, 1 casos por 100 mil habitantes e superando o número de homicídios dolosos. No entanto, reconhece-se que tais dados ainda são subdimensionados, devido ao constrangimento e aos próprios trâmites burocráticos do sistema judiciário que culmina no processo de sobrevitimização ${ }^{6}$. Além disso, $\operatorname{Costa}^{7}$ alerta que, no âmbito da violência familiar, a maioria dos casos não é denunciada.

Por outro lado, há um despreparo por parte dos profissionais de saúde que não sabem lidar com tal situação. A lei no 12.845 de $2013^{8}$ pretende normatizar estes atendimentos, tornando obrigatório e integral o atendimento de pessoas em situação de violência sexual. No tocante ao atendimento das mulheres, há uma maciça transferência do assunto para o setor de segurança pública ou o serviço social da instituição9.

Em casos de violência sexual que resultam na gravidez da vítima, o teste de paternidade se aplica com a finalidade de investigar o vínculo genético entre o pretenso filho e o suposto pai (neste caso, suspeito do crime). Atualmente, as investigações de vínculo genético e identificação humana têm como foco a análise de marcadores genéticos polimórficos presente no genoma nuclear, denominados de Repetições Curtas Consecutivas (STR, do inglês Short Tandem Repeats), devido à sua ubiquidade, amplificação pela técnica da Reação em Cadeia da Polimerase (PCR), relação de codominância entre os alelos ${ }^{10}$. Para a utilização em análises forenses, os STRs devem obedecer às premissas do Equilíbrio de Hardy-Weinberg (EHW) e leis de herança mendeliana.

$\mathrm{O}$ teste de paternidade visa a identificar os alelos de origem paterna obrigatória do pretenso filho e o compartilhamento destes alelos com o suposto pai ${ }^{11,12}$. Nos casos em que há o compartilhamento de alelos, calcula-se o peso da evidência genética por meio de um teste de hipóteses denominado, Índice de Paternidade (IP). O Índice de Paternidade, cuja fórmula é descrita abaixo, consiste na razão de verossimilhança de duas hipóteses mutuamente excludentes, a primeira hipótese (X) assume que o compartilhamento de alelos entre as partes resulta de um vínculo genético, enquanto a segunda hipótese $(\mathrm{Y})$ assume que o compartilhamento de alelos entre as partes é resultado de eventos aleatórios, isto é, outro homem não relacionado com o suposto pai é o verdadeiro pai da criança ${ }^{10}$.

$$
\mathrm{IP}=\mathrm{X} / \mathrm{Y} \quad \text { Equação } 1
$$

O IP é calculado para cada locus analisado e, por conseguinte, é aplicada a regra do produto para os resultados obtidos, isto porque, os mesmos consistem de eventos independentes. O resultado obtido a partir do produto dos IPs é denominado de Índice de Paternidade Combinado (IPC), cuja fórmula está descrita abaixo.

$$
\text { IPC }=\text { IP1 } x \text { IP2 } \times \text { IP3.x IPn Equação } 2
$$

De posse do IPC é possível calcular a Probabilidade de Paternidade (W, do alemão Wahrscheinlichkeit) por meio do Teorema de Bayes, tendo como base uma probabilidade a priori (PP) de 0,5, descrita abaixo.

$$
\mathrm{W}=(\mathrm{PP}) \times(\mathrm{IPC}) /\{[(\mathrm{PP}) \times(\mathrm{IPC})]+1\} \quad \text { Equação } 3
$$

Contudo, inconsistências mendelianas podem ocorrer em alguns casos, quando a razão de verossimilhança não é suficiente para corroborar a não exclusão de paternidade ou quando uma ou duas inconsistências alélicas são observadas. Neste caso, é possível que o pretenso filho e o suposto pai sejam parentes próximos, dessa forma o verdadeiro pai pode ser o suposto tio, sendo que para estas situações calcula-se o índice avuncular ${ }^{13}$.

Todavia, se a mãe do pretenso filho e o suposto pai são relacionados geneticamente, a probabilidade de paternidade pode ser afetada ${ }^{14}$, caso a hipótese alternativa a ser considerada seja que o "verdadeiro pai do pretenso filho é um homem relacionado geneticamente com o suposto pai"15. Isto também reduz a capacidade em detectar um homem falsamente acusado e, em alguns casos incestuosos, pode produzir falsas inclusões de paternidade ${ }^{14,16}$.

(1) Art. 213. "Constranger alguém, mediante violência ou grave ameaça, a ter conjunção carnal ou a praticar ou permitir que com ele se pratique outro ato libidinoso:" 
Em casos incestuosos é importante distinguir quando os alelos são idênticos por estado (IBS) e quando são idênticos por derivação (IBD). Os alelos IBS são aqueles não derivados de um ancestral recente comum conhecido, como exemplificado na figura 1, no heredograma do lado esquerdo. Neste caso, o alelo A1 presente nos filhos é oriundo de genitores diferentes. Os alelos IBD são demonstravelmente cópias do mesmo alelo ancestral, como demonstrado no heredograma do lado direito da figura 1. Em casos de paternidade incestuosos não é possível determinar se os alelos compartilhados entre o suposto pai e o pretenso filho são IBS ou IBD, mas o cálculo do índice de paternidade deve considerar outros parâmetros uma vez que o genótipo da mãe e do suposto pai não são independentes.

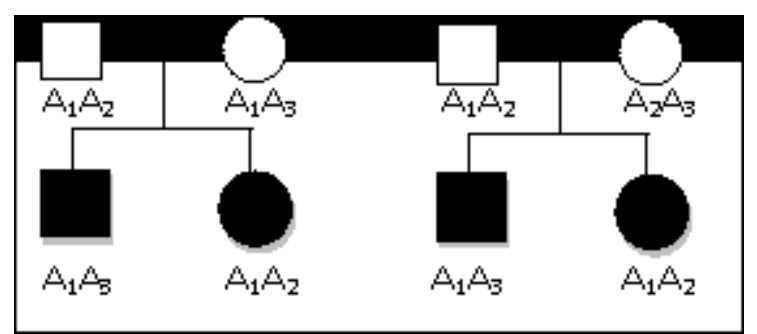

Figura 1 - Ambos os pares de irmão compartilham o alelo A1. O primeiro par compartilha duas cópias independentes (IBS, mas não IBD), enquanto o segundo par compartilha cópias do mesmo alelo paterno A1 (IBD). A diferença é aparente se o genótipo dos pais é conhecido

No presente trabalho, apresenta-se uma análise comparativa entre duas abordagens matemáticas para casos de paternidade incestuosos (pai e filha) cujos resultados não excluíram a paternidade. A primeira abordagem consistiu em considerar como hipótese alternativa em que um homem não relacionado poderia ser o verdadeiro pai do pretenso filho e a segunda considerava a probabilidade dos alelos compartilhados entre o suposto pai e o pretenso filho serem oriundos de um homem relacionado à genitora, denominado de Índice de Incesto (II), sendo aplicada a regra do produto para estes e obtendo o valor de Índice Combinado de Incesto (ICI). Dessa forma, pretendeu-se valorar a relação entre as duas abordagens, calculando-se a razão IPC/ICI para detectar possíveis superestimativa em algum dos cenários.

\section{MATERIAL E MÉTODOS}

Extração de DNA: O material biológico utilizado foi sangue periférico imobilizado em papel FTA ${ }^{\circledR}$ (Watchman) e a extração executada por meio de procedimentos de lavagem com tampão FTA ${ }^{\circledR}$ (Watchman) por 40 minutos sob constante homogeneização e, por conseguinte, lavagem com água destilada por 15 minutos sob as mesmas condições acima.

Reação em Cadeia Polimerase: As seguintes regiões gênicas, D8S1179, THO1, TPOX, D3S1358, D21S11, D18S51, D5S818, D16S539, D7S820, CSF1PO, vWA, FGA. D2S1338, D19S433 foram amplificadas. As condições de ciclagem da reação foram $95^{\circ} \mathrm{C}$ por 11 minutos, 25 ciclos de $94^{\circ} \mathrm{C}$ por 1 minuto, $59^{\circ} \mathrm{C}$ por 1 minuto, $72^{\circ} \mathrm{C}$ por 1 minutos e $60^{\circ} \mathrm{C}$ por 60 minutos.

Detecção dos Produtos de PCR: A detecção dos produtos de PCR foi realizada por meio de eletroforese em capilar no sequenciador automático 3500 (Life Technologies), em capilar de $36 \mathrm{~cm}$, polímero POP-4 (Life Technologies), tempo de injeção de 15 segundos, voltagem da eletroinjeção de $15 \mathrm{Kv}$ e temperatura do sistema de $60^{\circ} \mathrm{C}$. Os produtos de PCR foram pipetados em 8,7 $\mu \mathrm{L}$ de Hi-Di formamida (Life Technologies) e $0,3 \mu \mathrm{L}$ de Padrão interno de Peso Molecular GeneScan LIZ 500 (Life Technologies).

Análise dos Resultados: A análise dos resultados foi executada no Software GeneMapper ID-X.

Análise Matemática: Os resultados dos Índices de Incesto e dos Índices de Paternidade foram comparados em 14 loci em três casos de agressão sexual cujo suspeito era o pai da vítima (Tabela 1).Os cálculos referentes aos índices de incesto para todos os loci descritos no campo de resultados foram calculados de acordo com Minataka et $\mathrm{al}^{14}$, enquanto que os cálculos referentes ao índices de paternidade foram calculados com base na fórmula de Essen-Moller (modificada por Gürtler). Os valores do Índice de Paternidade Combinado e do Índice Combinado de Incesto foram calculados pela aplicação da regra do produto para os valores dos respectivos Índices de Paternidade e de Incesto para os loci analisados, conforme demonstrado na equação 1. Para os cálculos, foram utilizados as frequências alélicas descritas em Grattapaglia et $\mathrm{al}^{17}$.

\section{RESULTADOS E DISCUSSÃO}

Apesar de apenas três casos terem sido analisados, deve-se considerar que genericamente está implícita nos resultados a avaliação de casos em que o suposto pai testado não tenha relacionamento com a mãe do filho investigante, uma vez que, quando se avalia apenas o valor de IPC, o valor é o mesmo que se encontraria para este suposto pai não relacionado. Por outro lado, a fim de lançar um olhar sobre possíveis casos em que o verdadeiro pai não é o suposto pai testado, porém ambos têm parentesco com a vítima, foram calculados os índices avunculares para cada locus e índice avuncular combinado (dado não mostrado), sendo estes resultados inferiores ao índice de paternidade combinado.

Os resultados referentes aos Índices de Incesto 
na maioria dos loci foram inferiores aos Índices de Paternidade, entretanto, tal resultado se evidencia ao analisarmos os Índices Combinados de Incesto e de Paternidade. Nos três casos a razão entre o IPC e o ICI revelou uma diferença que pode alcançar mais de 7 mil vezes. Ressalta-se que, usualmente, os laboratórios de análise liberam laudos conclusivos para não exclusão de paternidade com ÍPC de 10.000. Dessa maneira, os casos 2 e 3 seriam considerados como inconclusivos no cenário explicitado (Tabela 1).

Tabela 1 - Análise Comparativa dos Resultados Referentes ao Índice de Incesto e de Paternidade

\begin{tabular}{|c|c|c|c|c|c|c|c|c|c|c|c|}
\hline \multicolumn{3}{|c|}{ Caso 1} & & \multicolumn{3}{|c|}{ Caso 2} & & \multicolumn{3}{|c|}{ Caso 3} & \\
\hline \multicolumn{2}{|r|}{ II } & \multicolumn{2}{|l|}{ PI } & \multicolumn{2}{|r|}{ II } & \multicolumn{2}{|l|}{ PI } & \multicolumn{2}{|r|}{ II } & \multicolumn{2}{|l|}{ PI } \\
\hline D3S1358 & 1,3298 & 3,9683 & & & 1,3298 & 3,9683 & & & 1,7123 & 1,7123 & \\
\hline THO1 & 4,0323 & 4,0323 & & & 1,3089 & 1,3089 & & & 1,3850 & 2,2523 & \\
\hline D21S11 & 1,5962 & 3,9526 & & & 1,3280 & 1,9763 & & & 1,0638 & 1,0638 & \\
\hline D18S51 & 1,0000 & 3,413 & & & 0,8818 & 3,7313 & & & 3,7313 & 4,4248 & \\
\hline D5S818 & 1,5244 & 1,5244 & & & 1,0000 & 2,6247 & & & 1,2077 & 3,0488 & \\
\hline D7S820 & 333,3333 & 166,6667 & & & 1,3228 & 1,9531 & & & 3,0864 & 3,0864 & \\
\hline D16S539 & 1,5244 & 3,2051 & & & 1,5873 & 1,5873 & & & 3,2051 & 3,2051 & \\
\hline CSF1PO & 1,5337 & 1,5337 & & & 0,0455 & 1,6287 & & & 0,7541 & 1,5337 & \\
\hline vWA & 1,0000 & 4,8309 & & & 3,6496 & 3,6496 & & & 2,7174 & 2,7174 & \\
\hline D8S1179 & 4,0816 & 2,0408 & & & 4,0816 & 4,0816 & & & 1,2136 & 1,2136 & \\
\hline TPOX & 0,8757 & 1,0142 & & & 1,0000 & 1,3587 & & & 1,0582 & 2,2472 & \\
\hline FGA & 0,0043 & 0,0043 & & & 3,3333 & 3,3333 & & & 1,0000 & 3,4602 & \\
\hline D19S433 & 1,5193 & 1,5193 & & & 4,2212 & 2,1106 & & & 1,0000 & 2,2427 & \\
\hline \multirow[t]{3}{*}{ D2S1338 } & 1,7416 & 6,7385 & & & 6,7385 & 6,7385 & & & 9,0416 & 9,0416 & \\
\hline & 10829,2883 & IPC & 22988614,48 & $\mathbf{I C I}$ & 207,7211 & IPC & 1512574,027561 & ICI & 3457,8879 & IPC & 4123,1552 \\
\hline & 99,9908 & w & 99,999996 & w & 99,5209 & $\mathbf{w}$ & 99,999934 & w & 99,9711 & w & 99,9998 \\
\hline \multicolumn{2}{|r|}{ IPC/ICI } & 2122,819 & & \multicolumn{2}{|c|}{ IPC/ICI } & 7281,753 & & & IPC/ICI & 163,141 & \\
\hline
\end{tabular}

O ICI refletiu de maneira precisa o estado verdadeiro da natureza do caso (relação incestuosa versus relação aleatória) conforme se aumentava o número de loci analisados, sendo o aumento unidirecional nos três casos analisados.

Usualmente, em casos de paternidade, duas hipóteses são comparadas: o suspeito ser o pai biológico da criança em relação a outro homem não relacionado geneticamente com o suposto pai, mesmo quando os indivíduos são parentes, ser o pai. Os casos analisados dessa maneira tendem a gerar resultados superestimados, por não considerarem a possibilidade de os alelos compartilhados entre o suposto pai e o pretenso filho serem idênticos por descendência, isto é, o alelo ter sido transmitido pelo suposto pai para a mãe e dela para pretenso filho. O ICI, conforme descrito, apresentará resultados inferiores ao IPC quando aplicados a relações incestuosas do que em relação a casos envolvendo pessoas não relacionadas. Desta forma, se o limiar dos valores atribuídos aos cálculos for mais conservativo ou se a probabilidade de incesto for analisada, a resolução dos casos apresentará um aprimoramento estatístico, ou seja, livre de viés gerado pela consideração na hipótese alternativa de um homem não relacionado geneticamente.

\section{CONCLUSÃO}

A função de um teste de parentesco consiste em analisar em termos probabilísticos o vínculo genético entre dois indivíduos. Caso o vínculo genético não seja excluído, o peso da evidência genética pode ser calculado. Nos três casos analisados, o IPC foi superior ao ICI em ordem que alcançou $10^{3}$, mostrando que as análises usuais podem superestimar os resultados nos exames de vínculo genético. Grandeza suficiente para que, nos exames de paternidade, os resultados fossem considerados conclusivos para não exclusão de paternidade. Dessa forma, ao considerarmos os casos 2 e 3 na tabela 1 , verificamos que os ICI apresentam resultados que seriam considerados inconclusivos, demandando investigação complementar. Tal resultado está atrelado ao fato de que indivíduos relacionados têm maior possibilidade de compartilhar alelos.

Dessa forma, o estudo vem enaltecer a importância de analisar o cenário relacionado a incesto, de modo a evitar resultados superestimados nas análises, considerando como hipótese alternativa no cálculo de índice de paternidade, na qual o "verdadeiro pai do pretenso filho seja um homem relacionado geneticamente com o suposto pai”. 
Rodrigues EL; Garrido RG; Carvalho RM; Santos CVF; Santos CA. Associating the Incest and Paternity Index to discriminate sexual aggression among close blood relatives. Saúde, Ética \& Justiça. 2013;18(2):141-5.

\begin{abstract}
Sexual violence in Brazil, as well as being a heinous crime, is a public health issue. In the majority of cases of sexually abused children, close relatives are the most common aggressors. When a crime of a sexual nature results in pregnancy, a paternity test is the most reliable form of evidence. The purpose of this test is to verify the sharing of alleles between the child and alleged father, in order to assign probabilistic terms related to the transmission of alleles from the suspect in relation to an unrelated man in population - this is called the Paternity Index. However, in cases where the alleged father has a biological relationship with the victim, some mathematical parameters should be considered, in order to avoid overestimation of the values assigned to the indices of paternity. It becomes necessary to distinguish alleles identical by descent from those identical by state. From a comparative analysis of 3 incestuous cases, calculations of the Paternity Index were performed in the usual way, both considering the suspect as being unrelated to the victim, and considering the suspect as being related to the victim, and this calculation was named the Incest Index. The Combined Paternity Index was higher than the combined ratio of Incest by up to $10^{3}$ times, showing that the usual analysis may overestimate the results in the exams of genetic link. Thus, the use of this mathematical methodology is proposed for both incestuous scenarios, in order to avoid issuing overrated or erroneous statistical reports of incest.
\end{abstract}

KEYWORDS: Sexual violence; Paternity; Incest.

\section{REFERÊNCIAS}

1. Brasil. Presidência da República, Subchefia para assuntos jurídicos. Lei $\mathrm{n}^{\circ} 12.015$, de 7 de agosto de 2009. Dispõe sobre os crimes hediondos, nos termos do inciso XLIII do art. 5o da Constituição Federal e revoga a Lei no 2.252, de 10 de julho de 1954, que trata de corrupção de menores. Brasília, DF; 2009. Disponível em: http://www.planalto.gov. br/ccivil_03/_ato2007-2010/2009/lei/112015.htm

2. Delgado YM. Comentários à Lei n ${ }^{\circ} 12.015 / 09$. Jus Navigandi [Internet]. , 2009 [acesso em 4 dez 2013]. Disponível em: http://jus.com.br/artigos/13629

3. Rocha TCL, Torres JCN, Sobreira ACM, Brasil SMV, Cavalcante IA, Alencar VHM. A importância da coleta de material peniano do suspeito em casos de crimes sexuais: Um relato de caso. Saúde, Ética \& Justiça. 2013; 18(Ed. Especial):45-9. DOI: http://dx.doi.org/10.11606/issn.23172770.v18i1p

4. Antonio ERM, Fontes TMP. Bioética e aspectos epidemiológicos de vítimas de violência sexual em hospitalmaternidade. Revista Bioética. 2012; 20(2):280-87.

5. Fórum Brasileiro de Segurança Pública. Anuário Brasileiro de Segurança Pública. $7^{\mathrm{a}}$ ed. São Paulo: Fórum Brasileiro de Segurança Pública; 2013.

6. Faúndes A, Leocádio E, Andalaft-Neto J. Relatório Final: VII Fórum Interprofissional para Atendimento Integral da Mulher Vítima de Violência Sexual. Femina: Rio de Janeiro; 2004.

7. Costa DM. Gênero e mercocidades brasileiras: Violência contra a Mulher. Rio de Janeiro: Ibam/DES/Iser; 2003.

8. Brasil. Presidência da República, Subchefia para assuntos jurídicos. Lei $\mathrm{n}^{\circ} 12.845$, de $1^{\circ}$ de agosto de 2013. Dispõe sobre o atendimento obrigatório e integral de pessoas em situação de violência sexual. Brasília, DF; 2013. Disponível em: http://www.planalto.gov.br/ccivil_03/_ato20112014/2013/lei/112845.htm
9. Lerner T. Tratamento em situações de abuso sexual de crianças e adolescentes. Jornal da Rede Feminista de Saúde. 2000; 22: 29-32.

10. Butler JM. Forensic DNA Typing - Biology, Technology and Genetics of STR Markers. $2^{\mathrm{a}}$ ed. London: Elsevier Academic Press; 2005.

11. Morling N, Allen RW, Carracedo A, Geada H, Guidet F, Hallenberg C, et al. Paternity testing commission of the international society of forensic genetics: recommendations on genetic investigations in paternity cases. Forensic Sci Int. 2002; 129(3):148-57. DOI: http://dx.doi.org/10.1016/S03790738(02)00289-X

12. et al. ISFG: Recommendations on biostatistics in paternity testing. Forensic Sci Int Genet. 2007; 1(3-4):223-31. DOI: http://dx.doi.org/10.1016/j.fsigen.2007.06.006

13. Magalhães M, Pinto N, Gomes C, Pereira R, Amorim A, Alves $\mathrm{C}$, et al. When the alleged father is a close relative of the real father: The utility of insertion/deletion polymorphisms. Forensic Sci Int Genet Suppl Series. 2011; 3(1):e9-e10. DOI: http://dx.doi.org/10.1016/j.fsigss.2011.08.004.

14. Minataka K, Ishitani A, Ito N, Nagaike C, Morimura Y, Hatake K, et al. Paternity probability in the cases of incest. Nihon Hoigaku Zasshi. 1996; 50(3):149-55.

15. Evett IW, Weir BS. Interpreting DNA Evidence: Statistical Genetics For Forensic Scientists. $1^{\text {st }}$ ed. Sinauer Associates: Sunderland, MA (EUA); 1998.

16. Morris JW, Garber RA, D'Autremont, J, Brenner CH. The Avuncular Index and the Incest Index. Advances in Forensic Haemogenetics. 1988; 2:607-11.

17. Grattapaglia D, Schmidt AB, Costa e Silva C, Stringher C, Fernandes AP, Ferreira ME. Brazilian Population database for the 13 STR loci of the AmpFISTR ${ }^{\circledR}$ Profiler Plus ${ }^{\mathrm{TM}}$ and Cofiler $^{\mathrm{TM}}$ multiplex kits. Forensic Science International. 2001; 118:91-4. 